\title{
Thermal constraints and optimization of winter feeding and habitat choice in white-tailed deer
}

\author{
Oswald J. Schmitz
}

Schmitz, O. J. 1991. Thermal constraints and optimization of winter feeding and habitat choice in white-tailed deer. - Holarct. Ecol. 14: 104-111.

I examined the activity and habitat choice of white-tailed deer in winter to determine how deer balance feeding in habitats which may expose them to cold with resting in sheltered habitats. Average heat gain or loss of deer for feeding, resting and walking in four habitats in each of $24 \mathrm{~h}$ were estimated for two winter periods (early-mid and late winter). These values were used in a dynamic optimization model to predict the hourly behavior-habitat choices which enable deer to maintain thermal homeostasis, minimize the risk of exceeding lethal body temperatures and satisfy daily energy requirements. The behavior and habitat choices observed under natural conditions were consistent with the model predictions. Deer foraged for the maximum time that was thermally possible in both sampling periods and they used exposed habitats without incurring high heat losses. Deer appeared to avoid overheating in sheltered habitats during daylight and avoid hypothermia in exposed habitats at night.

O. J. Schmitz, School of Natural Resources, Univ. of Michigan, Ann Arbor, MI 48109-1115, USA. Present address: Dept of Zoology, Univ. of British Columbia, Vancouver, B.C. Canada V6T $2 A 9$.

\section{Introduction}

Winter in temperate regions is considered critical for large endotherms such as deer because cold climatic conditions may increase the energetic cost of survival and the risk of hypothermia (Moen 1973, 1976, Mautz 1978, Bartholomew 1980, Short 1981, Parker and Robbins 1984, Verme and Ullrey 1984). Also, the quality and abundance of food tends to be low so deer may not satisfy energy requirements for survival (usually 1.8-2 $\times$ basal metabolic requirements [Short 1981, Moen 1985]) simply by feeding (Mautz 1978, Parker and Robbins 1984).

Deer cope with the energetic demands of winter in several ways. They minimize their energy requirements by reducing metabolic rates and body temperatures and by spending more time resting in conifer shelter (Moen 1968a, 1976, 1985, Staines 1976, Turner 1979, Euler and Thurston 1980, Gates and Harman 1980, Cederlund 1981, Risenhoover 1986). They also rely on body fat to help satisfy energy requirements (Mautz 1978, Verme and Ullrey 1984). Even so, deer do not have sufficient fat reserves to satisfy requirements for an entire winter without foraging (Mautz 1978).

Forage abundance, however, is very low in conifer stands (Verme 1965). Thus, deer must leave shelter and become exposed to habitats which potentially result in high heat losses (Verme 1965, Ozoga 1968, Moen 1976). Consequently, deer face an important trade-off: they must balance the need to rest in shelter, to conserve energy, with the need to forage in more exposed habitats to meet energy demands (Moen 1976, Mautz 1978, Gates and Hudson 1979, Parker and Robbins 1984).

Although Moen (1968a, 1968b) examined the influence of the winter thermal environment on deer activity, his study was restricted to nighttime when deer predominantly rest. Therefore, it is not entirely clear how deer balance foraging with resting to survive the winter. The purpose of this study was to determine how the winter thermal environment influences feeding activity in white-tailed deer Odocoileus virginianus. 
Tab. 1. Characteristics of various habitat types measured in the Loring study area.

\begin{tabular}{lcc}
\hline Habitat type & $\%$ Cover & $\begin{array}{c}\text { Twig biomass } \\
\left(\mathrm{g} \mathrm{m}^{-1}\right)^{*}\end{array}$ \\
\hline $\begin{array}{l}\text { Open } \\
\begin{array}{l}\text { Deciduous } \\
\text { Mixed coniferous- } \\
\text { deciduous }\end{array}\end{array}$ & 0 & $7.6-9.5$ \\
Coniferous & $1-30$ & $6.5-7.5$ \\
\hline
\end{tabular}

* a twig was defined as that part of the stem representing current annual growth.

The time allocated to feeding will depend on the foraging strategy. Deer could either feed for as much time as possible each day (called feeding-time maximization, Schoener [1971], Belovsky [1978]) or for the least amount of time needed to satisfy daily energy requirements (called feeding-time minimization, Schoener [1971], Belovsky [1978]).

Feeding-time maximization is appropriate if high fat levels are required for reproduction or to survive when snow conditions restrict access to food resources or make the energetic cost of foraging greater than the return (Mattfeld 1974, Moen 1976, Parker et al. 1984). The amount of time deer can feed will be constrained, however, because they must avoid excessive heat loss or gain and they cannot feed when the gut is filled. Time minimization is appropriate if it improves survivorship by minimizing the time exposed to deleterious climatic conditions (cold temperatures and winds) or predators.

Accordingly, both feeding-time maximizers and time minimizers should feed in habitats and time periods with the lowest costs and risks. When not feeding, a feeding-time maximizer should adopt behaviors that enable it to resume feeding as quickly as possible. A time minimizer should adopt the behavior that expends the least energy. I estimated the optimal activity-habitat choice for a time maximizer and time minimizer and compared the predictions with behavior of deer in the field.

\section{Methods}

\section{Study area}

The study was conducted in the winters of 1986 and 1987 in the Loring deer yard in east-central Ontario, Canada $\left(46^{\circ} \mathrm{N}, 80^{\circ} \mathrm{W}\right)$. The yard is near the northeastern limit of white-tailed deer range in Ontario. There is an abundance of mature hemlock Tsuga canadensis, northern white-cedar Thuja occidentalis, and balsam fir Abies balsamea for shelter. Deciduous browse includes several species of maple Acer spp., hazel Corylus cornuta, and yellow birch Betula alleghaniensis. The yard encompasses $525 \mathrm{~km}^{2}$ and supports at least 10,000 deer during the winter (Strathearn 1981). Stocker et al. (1977) de- scribe the physiography and vegetation of the study area in detail.

\section{Sampling periods}

The winter was subdivided into two sampling periods: 1) early-mid winter (early January to late February); and 2) late winter (mid March to mid April). These periods provided different thermal environments for deer. At the latitude of the study area average temperatures are -15 to $-20^{\circ} \mathrm{C}$ in early-mid winter and 0 to $-8^{\circ} \mathrm{C}$ in late winter, average daylength is $9 \mathrm{~h}$ and $12.5 \mathrm{~h}$ in early-mid and late winter respectively, and average daily solar insolation on a flat surface is 5 and $12 \mathrm{MJ} \mathrm{m}^{-2}$ in early-mid and late winter respectively (Anon. 1985). Furthermore, metabolic rates (heat production) of deer are reduced in early-mid winter and increase in late winter (Moen 1985). These factors will lead to differences in the thermal energy budget between sampling periods.

\section{Behavior and habitat choice}

Behavior was categorized as resting (lying, ruminating and standing), feeding and active (walking or running) because each has a different energetic cost (Moen 1973, Mautz and Fair 1980). Resting minimizes heat loss in winter (Moen 1973, 1976). Ruminating is usually conducted while lying or standing (Turner 1979, Cederlund 1981, Risenhoover 1986 unpubl. data). Walking or running generates heat that can offset dramatic heat losses due to prolonged exposure to cold (Ozoga and Gysel 1972, Moen 1976, Gates and Hudson 1979, Rogers et al. 1987).

I observed deer activity each hour, during daylight hours (0600-1800) both from incidental encounters while travelling throughout the study area and by walking along transects through various habitats during randomly selected time periods of the day. I could not observe behavior at night because deer usually ran away from spotlights or they were startled and became inactive. Thus, I monitored 12 deer using radio telemetry.

The deer were fitted with radio collars (Lotek Engineering, Aurora, ON) containing standard mercury tip switches (Beier and McCullough 1988) which could detect head movements. Individual animals were monitored 2-5 min every hour during three $24 \mathrm{~h}$ periods in early-mid and late winter respectively. This method accurately distinguishes between resting and activity $98 \%$ of the time (Beier and McCullough 1988).

Because data from radio-collared deer could not indicate the type of activity I used observations of daytime foraging and nonforaging activity to separate telemetrymonitored activity into feeding and non-feeding components. I estimated the observed, average proportion of active deer feeding during daylight and converted the telemetry activity measure into a proportion feeding each hour. This assumes that deer feed at night which 
they do (Montgomery 1963, Ozoga and Verme 1970, Gilbert and Bateman 1983).

I estimated average daily feeding time $\left(T_{f} \operatorname{min~}^{-1}\right)$ for each winter sampling period using the formula (Belovsky and Slade 1986):

\section{$\mathrm{T}_{\mathrm{f}}=\left(\left(\Sigma \mathrm{p}_{\mathrm{i}}\right) / 24\right) \times 1440 \mathrm{~min} \mathrm{~d}^{-1}$}

where $p_{i}$ is the ratio of the number of individuals observed feeding in hour $i$ to the maximum number of individuals observed feeding in any hour.

During daylight, I also recorded the habitat in which deer were observed. Deer had access to four habitats that differed in shelter value and food abundance (Tab. 1). Much of the deciduous browse was in fields or areas opened by logging (open habitat) and deciduous habitats. Both deciduous and coniferous browse occurred in mixed coniferous-deciduous habitats. These habitats also provided moderate shelter. Finally, maximum shelter was provided in coniferous habitats.

\section{Measurement of thermal parameters}

I used a thermodynamic model (Porter and Gates 1969, Gates 1980) to estimate the net heat exchange (gain or loss) between deer and their environment for each potential behavior and habitat in each hour of an average day. To solve the model, I measured total shortwave radiation (wavelength $0.3-3 \mu \mathrm{m}$ ), ambient air temperature, vegetation and snow surface temperatures and wind velocity in the field.

I measured total incoming shortwave radiation (W $\mathrm{m}^{-2}$ ) using a Robitzsch-type mechanical pyranograph (Weather Measure Corp. Sacramento CA) with a 2-5 min time lag depending on the degree of cloud cover. This time lag was not a limitation since I was only concerned with average hourly values and not instantaneous measures. The pyranograph was stationed on a 3 $\mathrm{m}$ platform in the open to avoid obstructions which may cast shadows or reflect radiation onto the instrument. I measured shortwave radiation for three $24 \mathrm{~h}$ periods in both early-mid and late winter. Measurements were made on 2 overcast days $(50 \%$ and $100 \%)$, and one clear day. I estimated average incoming shortwave radiation by weighting the measurements for clear and overcast days by the proportion that each occurred in the winter sampling periods.

Because the pyranograph was not portable, I estimated hourly radiation in each of the four habitats indirectly. I used a selenium photocell light meter (E. Leitz, GMBH Wetzlar, Germany) to measure the proportion of maximum downward radiation present in each habitat. Each hour, light meter readings were taken in the open to determine a standard maximum level. Subsequent readings in each of the 4 habitats were recorded as a percentage of the maximum standard for that hour. Readings were taken by pointing the photocell directly upward. Twenty readings were taken at 10 $m$ intervals along transects in each habitat type respectively. This sample size is sufficient to obtain a representative mean value for a habitat (Reifsnyder and Lull 1965). This method also assumes that downward visible radiation (measured with the light meter) is correlated with downward shortwave radiation which appears to be the case (Reifsnyder and Lull 1965).

Hourly light meter readings for each habitat were multiplied by the average hourly shortwave radiation, measured with the pyranograph. Shortwave radiation had to be separated into direct and indirect (diffuse) components (Porter and Gates 1969). In winter at the latitude of the study area, direct and indirect shortwave radiation is $75 \%$ and $25 \%$ of total shortwave radiation respectively (Gates 1980).

I measured air temperature with an electronic thermistor gas/air probe (Cole Parmer, Chicago IL). Twenty measurements were taken and averaged. I measured vegetation and snow surface temperatures by touching a $2 \mathrm{~mm} \varnothing$ electronic thermistor surface probe (Cole Parmer, Chicago, IL) on the vegetation or snow surface. Twenty temperature measurements were taken for each medium in each habitat.

Wind velocity was measured with a cup anemometer (Casella, London England), accurate to $0.5 \mathrm{~m} \mathrm{~s}^{-1}$, at 1 $\mathrm{m}$ above the snow surface. Twenty random samples were taken and averaged.

\section{Thermal constraints and predicting optimal behavior}

I used the hourly estimates of heat gain or loss in a dynamic programming model (Belovsky 1981b) to predict the optimal combination of behavior-habitat choices that would allow deer to maximize and minimizing feeding time for the least possible thermal cost and risk. Heat gain/loss is a suitable measure of cost because any deviation from zero net gain/loss (thermal homeostasis) requires energy expenditures for physiological adjustments (i.e. shivering, piloerection, vasodilation/vasoconstriction) to return to thermal homeostasis. I considered $3 \times 4$ potential behavior-habitat choices for each hour when solving the dynamic programming model.

Maximizing feeding time will be limited by three potential constraints. First, deer may gain or lose heat in different hours but the long term net gain or loss cannot exceed upper or lower lethal temperature limits. However, any unexpected activity (avoidance of predator attack or sudden exposure to unusually cold wind) could lead to death if body temperature was near the upper or lower lethal limits.

Therefore, deer would be expected to "set" upper and lower limits to provide a "margin for error" between acceptable limits and lethal limits (Belovsky 1981b). Parker and Robbins (1984) and Rogers et al. (1987) found that body temperature of free ranging deer in winter averaged $38^{\circ} \mathrm{C}$ but varied by c. $0.5^{\circ} \mathrm{C}$ when 


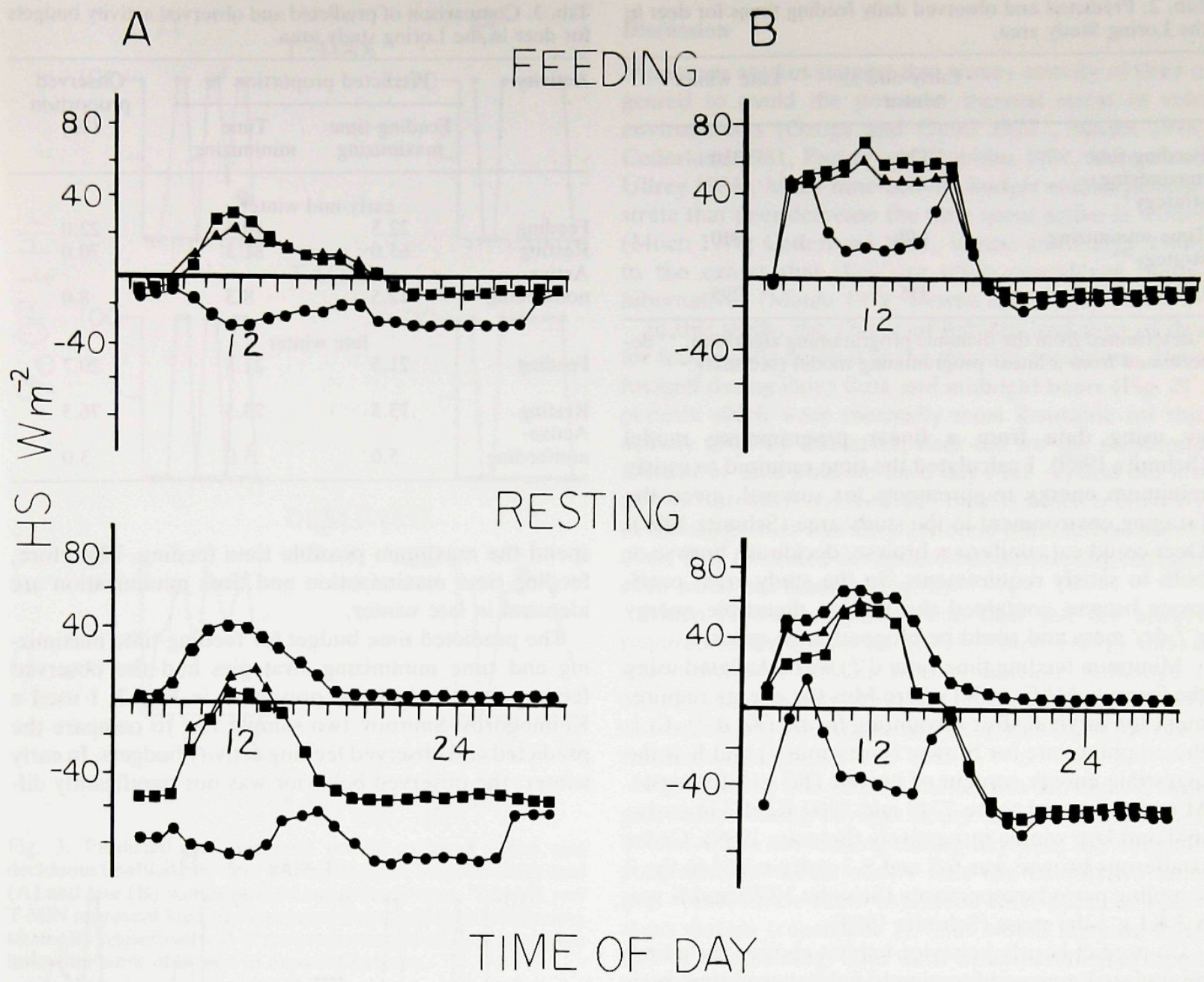

Fig. 1. Hourly heat gain or loss (HS) for feeding and resting in early-mid (A) and late (B) winter in the Loring study area. $=$ open habitat, $\boldsymbol{\square}=$ deciduous habitat, $\boldsymbol{\Delta}=$ mixed conifer deciduous habitat and $\mathbf{\theta}=$ conifer habitat.

deer activity ranged from lying to running in various habitats.

Assuming deer allow body temperature to drift by only $0.5^{\circ} \mathrm{C}$, the temperature constraint becomes:

$0.5^{\circ} \mathrm{Ch}^{-1} \geq\left|\sum_{i}^{n} \mathrm{HS}_{\mathrm{i}} / 26.6\right|$

where $\mathrm{HS}_{\mathrm{i}}$ is the heat gain or loss in hour $\mathrm{i}, \mathrm{n}$ is the number of hours being considered and $26.6 \mathrm{~W} \mathrm{~h} \mathrm{~m}^{-2}$ ${ }^{\circ} \mathrm{C}^{-1}$ is the heat energy needed to change the body temperature of an average deer $1^{\circ} \mathrm{C}$ (see Appendix).

Second, deer must also have a net heat gain/loss of 0 over a day to maintain thermal homeostasis. This constraint is:

$0=\sum_{i=1}^{24} \mathrm{HS}_{i}$
Finally, deer are limited by maximum rumen capacity (volume $\times$ daily turnover) and cannot eat continuously for a day. This constraint is:

$2194 \geq 6.6 \mathrm{~T}_{\mathrm{f}}$

for early-mid winter and:

\section{$2194 \geq 6.9 \mathrm{~T}_{\mathrm{f}}$}

for late winter where 2194 is the maximum daily rumen capacity (g-wet mass $\mathrm{d}^{-1}$ ) (Schmitz 1989), 6.6 and 6.9 are the cropping rates for twigs (g-wet mass $\mathrm{min}^{-1}$ ) in early-mid and late winter (Schmitz 1989) and $T_{f}$ is the daily feeding time $\left(\min ^{-1}\right)$.

I estimated feeding time for a time minimizing strategy using data from a linear programming model 
Tab. 2. Predicted and observed daily feeding times for deer in the Loring Study area.

\begin{tabular}{lcc}
\hline & $\begin{array}{c}\text { Early-mid } \\
\text { winter }\end{array}$ & Late winter \\
\hline $\begin{array}{l}\text { Feeding-time } \\
\text { maximizing } \\
\text { strategy* }\end{array}$ & 325 & 310 \\
$\begin{array}{l}\text { Time minimizing } \\
\text { strategy** } \\
\text { Observed }\end{array}$ & 140 & 310 \\
\hline
\end{tabular}

* determined from the dynamic programming algorithm. ${ }^{* *}$ determined from a linear programming model (see text).

gy using data from a linear programming model (Schmitz 1989). I calculated the time required to satisfy minimum energy requirements for survival, given the foraging environment in the study area (Schmitz 1989). Deer could eat coniferous browse, deciduous browse or both to satisfy requirements. In the study area, coniferous browse contained the highest digestible energy $\mathrm{g}^{-1}$-dry mass and could be cropped most quickly.

Minimum feeding time $\left(\mathrm{min}^{-1}\right)$ was calculated using the formula $\mathrm{M} /[\mathrm{Cr} \times \mathrm{K}]$ where $\mathrm{M}$ is the energy requirement for survival after accounting for fat $\left(\mathrm{KJ} \mathrm{d}^{-1}\right), \mathrm{Cr}$ is the cropping rate for browse (g-dry $\mathrm{min}^{-1}$ ) and $\mathrm{K}$ is the digestible energy content of browse ( $\mathrm{KJ} \mathrm{g}^{-1}$-dry mass). $M$ was estimated to be 7740 and $8400 \mathrm{KJ} \mathrm{d}^{-1}$ in earlymid and late winter respectively (Schmitz 1989), $\mathrm{Cr}$ for coniferous browse was 6.7 and $8.3 \mathrm{~g}$-dry $\mathrm{min}^{-1}$ in the 2 sampling periods respectively (Schmitz 1989) and K was $8.2 \mathrm{KJ} \mathrm{g}^{-1}$-dry mass (Schmitz 1989).

To predict hourly behavior-habitat choices for a time minimizer I assigned foraging to habitats and time periods with the lowest HS values until the minimum feeding time was achieved. The least costly non-feeding behaviors were allocated in each of the remaining hours until constraints 1 and 2 were satisfied.

\section{Results}

Heat gain/loss estimates for feeding and resting in different habitats are presented in Fig. 1. During certain hours of the day, deer can have a lower heat gain/loss while feeding in exposed habitats than resting in conifer shelter (Fig. 1).

The predicted maximum and minimum feeding times and observed feeding times are presented in Tab. 2. In both sampling periods, the time spent feeding approached the predicted maximum available feeding time. In late winter, the minimum time to satisfy requirements by feeding on coniferous browse was $123 \mathrm{~min}^{-1}$. However, the LP model showed deer could not consume enough conifer to satisfy requirements because of the digestive capacity limitations (Schmitz 1989). Therefore, they also had to consume deciduous browse. However, to satisfy requirements, they were required to
Tab. 3. Comparison of predicted and observed activity budgets for deer in the Loring study area.

\begin{tabular}{|c|c|c|c|}
\hline \multirow[t]{2}{*}{ Activity } & \multicolumn{2}{|c|}{ Predicted proportion \% } & \multirow{2}{*}{$\begin{array}{c}\text { Observed } \\
\text { proportion } \\
(\%)\end{array}$} \\
\hline & $\begin{array}{l}\text { Feeding-time } \\
\text { maximizing }\end{array}$ & $\begin{array}{c}\text { Time } \\
\text { minimizing }\end{array}$ & \\
\hline & \multicolumn{2}{|c|}{ early-mid winter } & \\
\hline Feeding & 22.5 & 10.4 & 22.0 \\
\hline Resting & 65.0 & 81.3 & 70.0 \\
\hline $\begin{array}{l}\text { Active- } \\
\text { nonfeeding }\end{array}$ & 12.5 & 8.3 & 8.0 \\
\hline \multicolumn{4}{|c|}{ late winter } \\
\hline Feeding & 21.5 & 21.5 & 20.7 \\
\hline $\begin{array}{l}\text { Resting } \\
\text { Active- }\end{array}$ & 73.5 & 73.5 & 76.3 \\
\hline nonfeeding & 5.0 & 5.0 & 3.0 \\
\hline
\end{tabular}

spend the maximum possible time feeding. Therefore, feeding time maximization and time minimization are identical in late winter.

The predicted time budget for feeding-time maximizing and time minimizing strategies and the observed feeding-time budget are presented in Fig. 2. I used a Kolmogorov-Smirnov two sample test to compare the predicted and observed feeding activity budgets. In early winter, the observed behavior was not significantly dif-

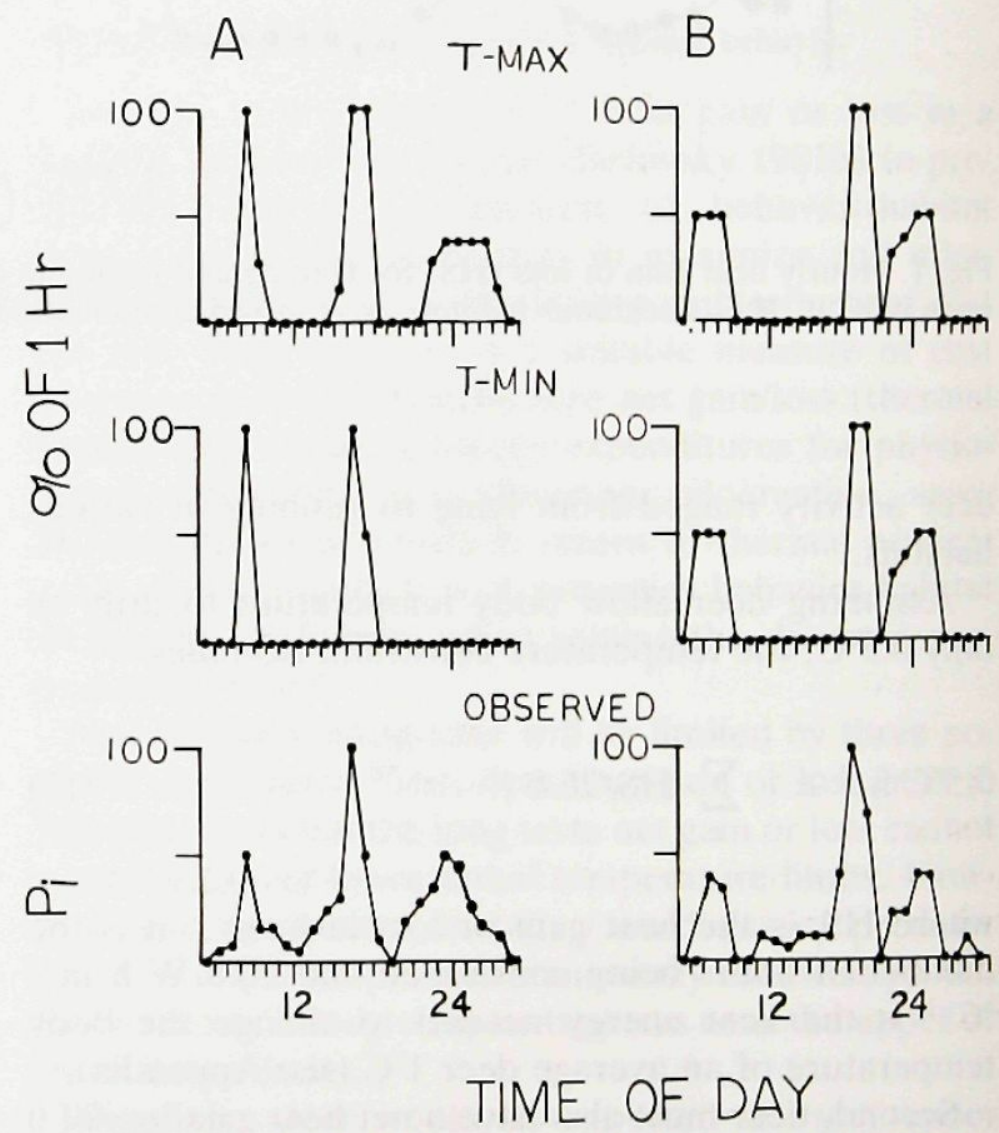

Fig. 2. Predicted and observed feeding time budgets for deer in early-mid (A) and late (B) winter in the Loring study area. T-MAX and T-MIN represent feeding-time maximizing and time minimizing strategies respectively. $\mathrm{P}_{\mathrm{i}}$ represents ratio of the number of deer observed feeding in a given hour to the maximum number of deer observed feeding in any hour. 


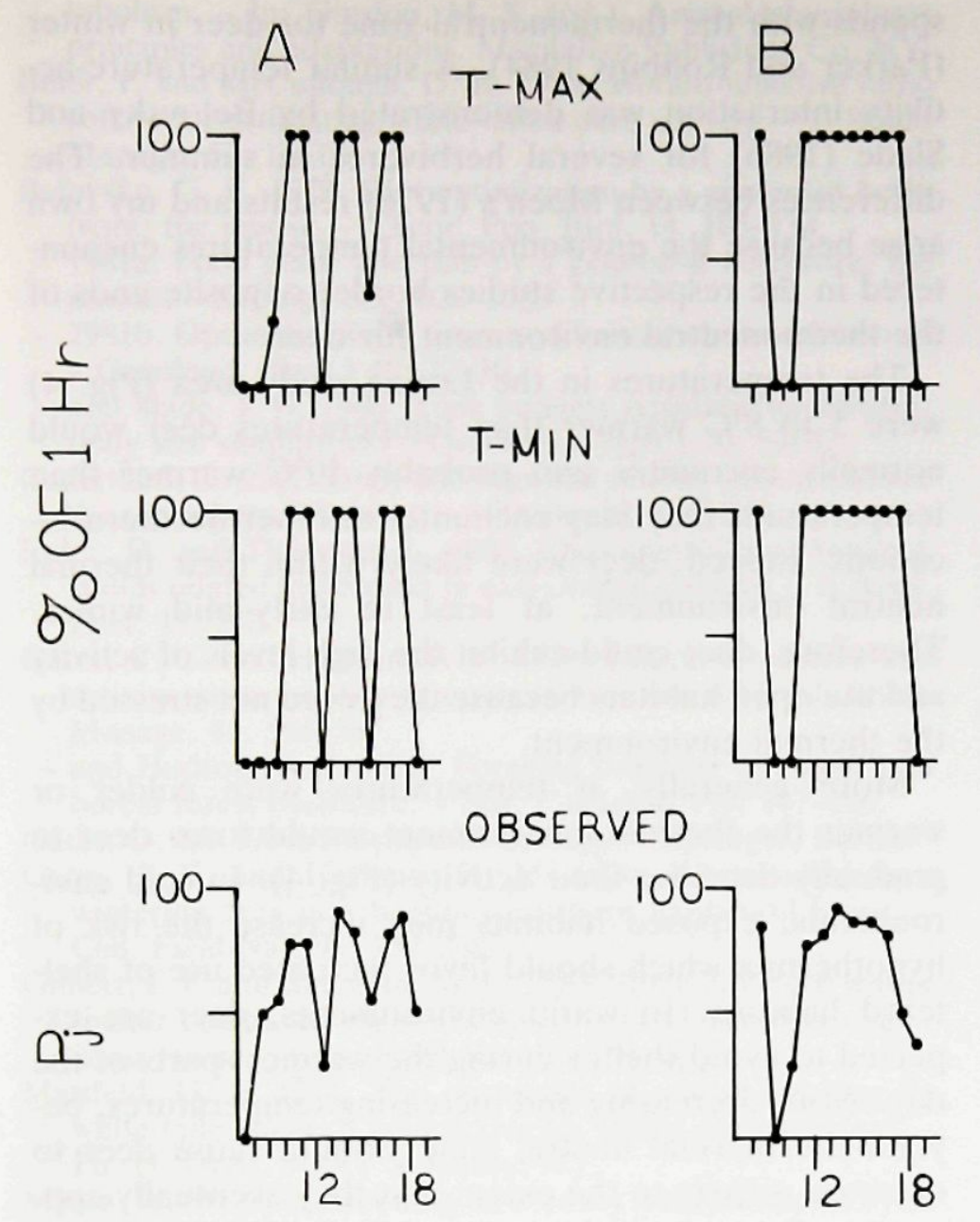

\section{TIME OF DAY}

Fig. 3. Predicted and observed use of exposed (open and deciduous) habitats by deer during daylight hours in early-mid (A) and late (B) winter in the Loring study area. T-MAX and T-MIN represent feeding-time maximizing and time minimizing strategies respectively. $\mathrm{P}_{j}$ is the proportion of all deer in a given hour that were observed in exposed habitats.

ferent from the feeding-time maximizing strategy $(\mathrm{p}>$ $0.05)$. The observed behavior was significantly different from the predicted time minimizing strategy $(\mathrm{p}<0.01)$. The predicted feeding-time budgets for the two strategies are indistinguishable in late winter. Also, the predicted and observed time budgets were not significantly different $(\mathrm{p}>0.05)$.

The predicted and observed hourly habitat choices for daylight hours are presented in Fig. 3. In both sampling periods, the predicted hourly habitat choices are similar for both feeding-time maximizing and time minimizing strategies. Deer were expected to remain predominantly in exposed habitats during daylight hours even when not foraging.

Finally, the predicted and observed proportion of time engaged in various behaviors is presented in Tab. 3. Despite feeding for the maximum available time, deer still appeared to be inactive for the greatest proportion of a day.

\section{Discussion}

Numerous studies suggest that winter activity of deer is geared to avoid the potential thermal stress of cold environments (Ozoga and Gysel 1972 , Mautz 1978, Cederlund 1981, Parker and Robbins 1984, Verme and Ullrey 1984). Many time-activity budget studies demonstrate that deer decrease the time spent active in winter (Moen 1976, Cederlund 1981, Verme and Ullrey 1984) to the extent that they are often considered "semihibernative" (Mautz 1978, Verme and Ullrey 1984).

In this study, the choice of habitats and time of day for feeding was related to the thermal conditions. Deer foraged during dawn dusk and midnight hours (Fig. 2), periods which were thermally most favorable for this activity (Fig. 1). However, deer fed for the maximum amount of time possible each day (Tab. 2) and did not always rest when not feeding (Tab. 3) which is contrary to the suggestion that they are semi-hibernative. Moreover, they remained in exposed habitats during daylight even when not feeding (Fig. 3).

Moen (1968a) suggested that deer did not always require conifer shelter in winter if their energy intake was sufficient to sustain heat production. Although a related study in the Loring deer yard (Schmitz 1989) shows deer have adequate nutrition, this study provides another explanation.

Fig. 1 shows that conifer shelter has the highest heat gain values during daylight hours. If deer rested in this habitat when not feeding during daytime, the dynamic programming model shows that the cumulative heat gain would cause them to exceed their upper temperature margin (constraint 1 ). This would increase their risk of overheating. The data demonstrate that open habitats (deciduous or open) are less thermally costly and risky at least during daylight. Thus, exposed habitats do not always present deleterious climates for wintering deer regardless of nutrition. When temperatures become colder (e.g. nighttime) conifer shelter becomes the least thermally costly habitat and animals are expected to spend most of the time in shelter to avoid hypothermia. Therefore, the tradeoff in winter involves balancing feeding with resting to avoid both excessive heat loss and gain. Restricting analyses of thermal budgets to nighttime only (e.g. Moen 1968a, 1968b) can produce a very different perception about the effects of winter thermal environments on deer activity and survival.

Deer also demonstrated the ability to adjust their activity and habitat choices in response to changes in the thermal environment between winter periods. In late winter, the hourly heat gains/losses were higher than in early-mid winter (Fig. 1) indicating a tendency for a warmer environment. In late winter, deer decreased the time spent foraging and proportion of time active (Tab. $3)$. This was necessary since the warmer environment increased the risk that deer would overheat if they re- 


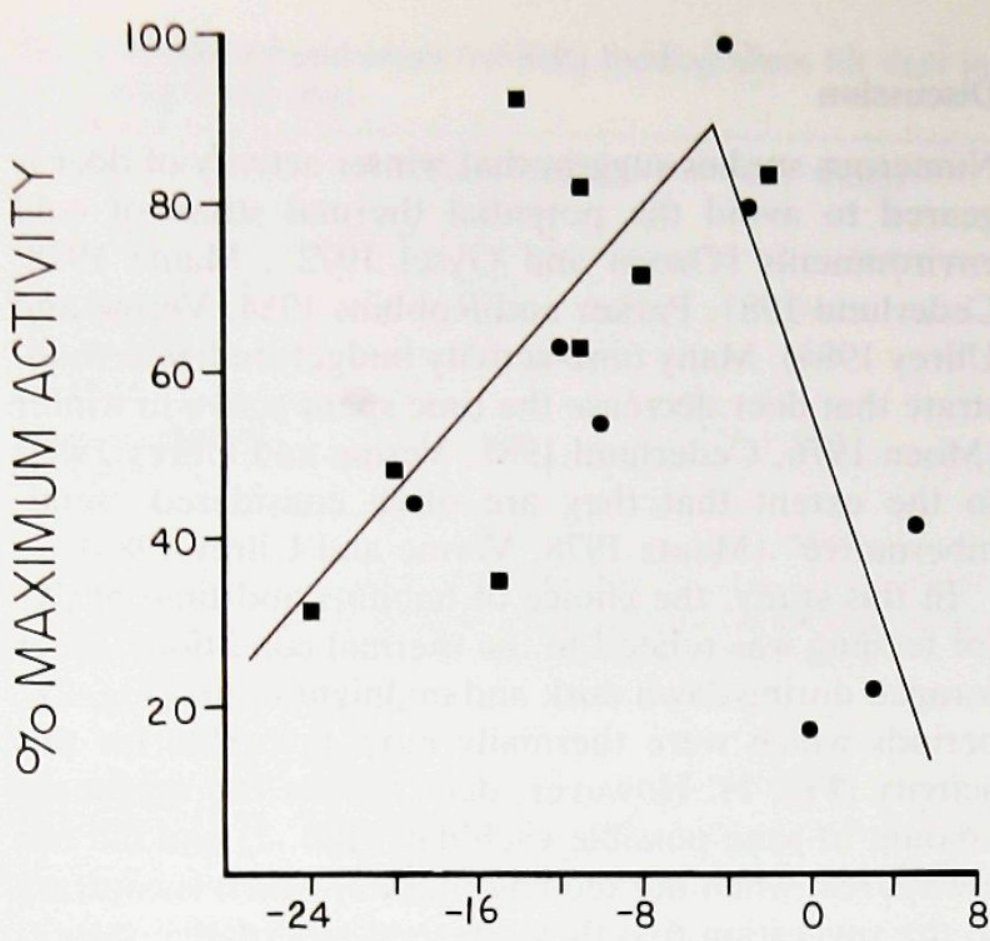

\section{TEMPERATURE $\quad{ }^{\circ} \mathrm{C}$}

Fig. 4. Overall activity as a function of environmental temperature during winter. represent data obtained from Moen (1976) and are data obtained in this study.

mained active for the same amount of time as early-mid winter.

This tendency to decrease activity levels when it becomes warmer contradicts earlier studies which show deer activity should decrease in colder environments (Moen 1976, Cederlund 1981, Verme and Ullrey 1984). However, other studies indicate that activity increases in winter in some deer species (Turner 1979, Belovsky 1981a, Gates and Hudson 1983).

To reconcile these differences, I examined activity data over a broad range of air temperatures. I used data collected in this study and from Moen (1976). Moen's (1976) activity measures and my own were not comparable in their original form. Moen (1976) measured activity using a track index whereas my data represented direct counts of active deer. I therefore scaled the activity data in each respective study as a proportion of maximum activity using the formula $p_{j}=a_{j} / a_{\max }$ where $a_{j}$ is the activity in time period $\mathrm{j}$ and $\mathrm{a}_{\max }$ is the maximum activity observed in any time period in the winter. These proportions were then plotted in relation to the mean temperature for the respective time period (Fig. 4). This is not to imply that temperature alone influences activity: it does, however, indicate the magnitude of the heat gain/loss deer likely incur when active (Moen 1976, Belovsky 1981b, Parker and Robbins 1984).

Fig. 4 shows a distinct temperature-activity interaction. Below $-12^{\circ} \mathrm{C}$, activity decreases with decreasing temperature and above $-1^{\circ} \mathrm{C}$ activity decreases with increasing temperature. The intermediate temperature range, exhibiting the highest levels of activity, corre- sponds with the thermoneutral zone for deer in winter (Parker and Robbins 1984). A similar temperature-activity interaction was demonstrated by Belovsky and Slade (1986) for several herbivores in summer. The differences between Moen's (1976) results and my own arise because the environmental temperatures encountered in the respective studies border opposite ends of the thermoneutral environment for deer.

The temperatures in the Loring study area (Fig. 4) were 5 to $8^{\circ} \mathrm{C}$ warmer than temperatures deer would normally encounter and probably $10^{\circ} \mathrm{C}$ warmer than temperatures they may encounter at other northern locations. Indeed, deer were likely within their thermal neutral environment, at least in early-mid winter. Therefore, deer could exhibit the high levels of activity and use open habitats because they were not stressed by the thermal environment.

More generally, if temperatures were colder or warmer the thermal environment would force deer to gradually decrease their activity (Fig. 4). In cold environments, exposed habitats may increase the risk of hypothermia which should favor increased use of sheltered habitats. In warm environments, deer are expected to avoid shelter during the warmest parts of the day. Also, decreasing and increasing temperatures, beyond the thermal neutral zone, should cause deer to decrease activity to the extent that they eventually approach a time minimizing strategy.

Nevertheless, it still may be possible to satisfy food requirements in these environments. Consequently, the thermal environment cannot be considered stressful until it prevents deer from feeding long enough each day to satisfy requirements (see also Moen 1968a).

Acknowledgments. - I wish to thank S. Dosser for helping collect the data and G. E. Belovsky, R. W. Gensemer, J. Hamr, M. E. Ritchie, B. Stockhoff and D. R. Voigt for commenting on various aspects of the study. The work was supported by a Renewable Resources Research Grant from the Ontario Ministry of Natural Resources (OMNR) and by fellowships from the Univ. of Michigan Rackham Graduate School. Additional logistical support was provided by the Wildlife Research Section of the OMNR.

\section{Appendix}

The value 26.6 in equation 1 was calculated by assuming animal tissue has a heat capacity of $3.43 \mathrm{~J} \mathrm{~g} \mathrm{~g}^{-1}{ }^{\circ} \mathrm{C}^{-1}\left(0.82 \mathrm{cal} \mathrm{g}^{-1}{ }^{\circ} \mathrm{C}^{-1}\right.$ [Bartholomew 1980]) and an average-sized deer in the study area $(59,000 \mathrm{~g})$ has a surface area of $2.11 \mathrm{~m}^{2}$ (Moen 1973). Given an hour has $3600 \mathrm{~s}$, we arrive at the parameter value as follows:

$3.43 \mathrm{~J} \mathrm{~g}^{-1}{ }^{\circ} \mathrm{C}^{-1} \times 59,000 \mathrm{~g} \mathrm{deer}^{-1} \times 1$ deer $\left(2.11 \mathrm{~m}^{2}\right)^{-1}$ $\times 1 \mathrm{~h}(3600 \mathrm{~s})^{-1}=26.6 \mathrm{~W} \mathrm{~h} \mathrm{~m}{ }^{-2} \mathrm{C}^{-1}$

\section{References}

Anonymous 1985. National atlas of Canada, 5th edition. Energy, mines and resources Canada, Ottawa, Canada.

Bartholomew, G. A. 1980. Body temperature and energy me- 
tabolism. - In: Gordon, M. S. (ed.), Animal physiology: principles and adaptations. Macmillan Publishing Co, NY.

Beier, P. and McCullough, D. R. 1988. Motion-sensitive radio collars for estimating white-tailed deer activity. - J. Wildl. Manage. 52: 11-13.

Belovsky, G. E. 1978. Diet optimization by a generalist herbivore: the moose. - Theor. Pop. Biol. 14: 105-134.

- 1981a. Food plant selection by a generalist herbivore: the moose. - Ecology 62: 1020-1030.

- 1981b. Optimal activity times and habitat choice of moose. - Oecologia (Berl.) 48: 22-30.

- and Slade, J. B. 1986. Time budgets grassland herbivores: body size similarities. - Oecologia (Berl.) 70: 53-62.

Cederlund, G. 1981. Daily and seasonal activity patterns of roe deer in a boreal habitat. - Viltrevy 11: 315-353.

Euler, D. and Thurston, L. 1980. Characteristics of hemlock stands related to deer use in east-central Ontario. - J. Appl. Ecol. 17: 1-6.

Gates, C. C. and Hudson, R. J. 1979. Effects of posture and activity on metabolic responses of wapiti to cold. - J. Wildl. Manage. 43: 564-567.

- and Hudson, R. J. 1983. Foraging behavior of wapiti in a boreal forest enclosure. - Nat. Canadien 110: 197-206.

Gates, D. M. 1980. Biophysical ecology. - Springer, Berlin.

Gates, J. E. and Harman, D. M. 1980. White-tailed deer wintering area in a hemlock-northern hardwood forest. Can. Field-Nat. 94: 259-268.

Gilbert, F. F. and Bateman, M. C. 1983. Some effects of winter shelter conditions on white-tailed deer Odocoileus virginianus fawns. - Can. Field-Nat. 97: 391-400.

Mattfeld, G. F. 1974. The energetics of winter foraging by white-tailed deer: a perspective on winter concentration. Ph. D. Diss., SUNY Syracuse, NY.

Mautz, W. W. 1978. Sledding on a bushy hillside: the fat cycle in deer. - Wildl. Soc. Bull. 6: 88-90.

- and Fair, J. 1980. Energy expenditure and heart rate for activities of white-tailed deer. - J. Wildl. Manage. 44: 333342.

Moen, A. N. 1968a. Energy exchange of white-tailed deer western Minnesota. - Ecology 49: 676-682.

- 1968b. Surface temperatures and radiant heat loss from white-tailed deer. - J. Wildl. Manage. 32: 338-343.

- 1973. Wildlife ecology: an analytical approach. - WH Freeman and Co., San Francisco, CA.

- 1976. Energy conservation by white-tailed deer in the winter. - Ecology 57: 192-198.

- 1985. Energy metabolism of deer in relation to environmental variables. - Biology of deer production, Roy. Soc. of New Zeal. Bull. 22: 439-445.

Montgomery, G. G. 1963. Nocturnal movements and activity rhythms of white-tailed deer. - J. Wildl. Manage. 27: 422427.

Ozoga, J. J. 1968. Variations in microclimate in a conifer swamp deer yard in northern Michigan. - J. Wildl. Manage. 32: 574-585.

- and Gysel, L. W. 1972. Responses of white-tailed deer to winter weather. - J. Wildl. Manage. 36: 892-896.

- and Verme, L. J. 1970. Winter feeding patterns of penned white-tailed deer. - J. Wildl. Manage. 34: 431-439.

Parker, K. L. and Robbins, C. T. 1984. Thermoregulation in mule deer and elk. - Can. J. Zool. 62: 1409-1422.

- , Robbins, C. T. and Hanley, T. A. 1984. Energy expenditures for locomotion by mule deer and elk. - J. Wildl. Manage. 48: 474-488.

Porter, W. P. and Gates, D. M. 1969. Thermodynamic equilibria of animals with environment. - Ecol. Monogr. 39: 227244.

Reifsnyder, W. E. and Lull, H. W. 1965. Radiant energy in relation to forests. - US Dept of Agric., For. Serv. Tech. Bull. No. 1344.

Risenhoover, K. L. 1986. Winter activity patterns of moose in interior Alaska. - J. Wildl. Manage. 50: 727-734.

Rogers, L. L., Moen, A. N. and Shedd M. L. 1987. Rectal temperatures of two free-ranging white-tailed deer fawns. J. Wildl. Manage. 51: 59-62.

Schmitz, O. J. 1989. Environmental variability and optimal foraging behavior of a generalist herbivore: the whitetailed deer. - Ph. D. Diss., Univ. of Michigan, Ann Arbor. MI.

Schoener, T. W. 1971. Theory of feeding strategies. - Ann. Rev. Ecol. Syst. 2: 369-403.

Short, H. L. 1981. Nutrition and metabolism. - In: Wallmo, O. C. (ed.), Mule and black-tailed deer of North America. Univ. of Nebraska Press, Lincoln, NB, pp. 99-128.

Staines, B. W. 1976. The use of natural shelter by red deer in relation to weather in north-east Scotland. - J. Zool. Lond. 180: $1-8$.

Stocker, M., Gilbert, F. F. and Smith, D. W. 1977. Vegetation and deer habitat relationships in southern Ontario: classification of habitat type. - J. Appl. Ecol. 14: 419-432.

Strathearn, M. P. 1981. Deer management plan for wildlife management unit 47. - Ontario Minist. of Nat. Resour. Unpubl. Report.

Turner, D. C. 1979. An analysis of time-budgeting by roe deer (Capreolus capreolus) in an agricultural area. - Behavior 71: 246-290.

Verme, L. J. 1965. Swamp conifer deer yards in northern Michigan. - J. For. 63: 523-529.

- and Ullrey, D. E. 1984. Physiology and nutrition. - In: Halls, L. K. (ed.), White-tailed deer ecology and management. Stackpole Books, Harrisburg, PA, pp. 91-118. 
This document is a scanned copy of a printed document. No warranty is given about the accuracy of the copy. Users should refer to the original published version of the material. 